3. Каймонов М.В., Хохолов Ю.А., Курилко А.С., Необутов Г.П. Методика расчета послойного намораживания пород при формировании льдопородного массива в горных выработках // Горный информационно-аналитический бюллетень. 2003. № 9. С. 47-49.

4. Хохолов Ю. А., Мамонов А. Ф., Зубков В. П. Оптимизация формирования льдопородного массива в горных выработках Горный информационно-аналитический бюллетень. 2004. №10. С. 103-107.

5. Курилко А.С., Ермаков С.А., Хохолов Ю.А., Каймонов М.В., Бураков А.М. Моделирование тепловых процессов в горном массиве при открытой разработке россыпей криолитозоны. Новосибирск: Академическое изд-во «Гео», 2011. 140 с.

\title{
Наумов И.В., Шевченко М.В., Кожушко П.П. \\ Влияние несимметрии фазных токов в электрических сетях напряжением 0,38 кВ на пожарную опасность в жилых и производственных помещениях Амурской области
}

Дальневосточный государственный аграрный университет (Россия, Благовещенск)

doi: $10.18411 / \mathrm{j}-30-09-2017-24$

idsp: 000001:lj-30-09-2017-24

\section{Аннотация}

В статье представлен анализ влияния несимметрии фазных токов на пожарную опасность в жилых и производственных помещениях, и даны рекомендации по уменьшению количества пожаров связанных с неправильным распределением потребителей электрической энергии по фазам сети.

Ключевые слова: электрическая сеть,несимметрия фазных токов, ток нулевой последовательности, потребители электрической энергии.

Современный этап развития сельской электрификации характеризуется прогрессирующим ростом сельскохозяйственного производства и развитием коммунально-бытовой нагрузки - увеличением мощности нагрузок предприятий, развитием электротехнологии и автоматизации производственных процессов, а также повышением степени использования электрооборудования, в частности однофазных электроприёмников. В свою очередь, это влечет за собой постоянный рост потерь электрической энергии и мощности, как в распределительной сети, так и в самих электроприемниках. Одним из источников потерь, является несимметрия токов в сети и на зажимах электроприемников.

Основной причиной возникновения длительных несимметричных режимов электрических систем является несимметрия распределения потребителей электрической энергии по фазам сети. К таким потребителям в первую очередь следует отнести электротехнологические установки, преобладающее большинство которых, вследствие несимметричного исполнения и особенностей самого технологического процесса, обуславливает несимметрию режима питающей электрической сети, что отрицательно влияет на работу потребителей и ведет к ухудшению показателей качества электрической энергии. Подключение таких потребителей к электрической сети вызывает в последней несимметрию токов и напряжений, которая отрицательно сказывается на работе всех звеньев системы: генераторов, линий электропередачи и трансформаторов, приемников электроэнергии.[ 1 ]

Значительные токи нулевой последовательности, протекающие через нулевой проводник недостаточного сечения, могут вызвать его сильный нагрев. Сильный нагрев нулевого проводника приводит к однофазному короткому замыканию, что в случае неисправности или неверного выбора защитной аппаратуры приведет к возникновению возгорания.

Проведен анализ пожаров и их последствий в Амурской области за период 2006 2016гг в сельской и городской местности. Согласно данным предоставленным ГУ МЧС 
РФ по Амурской области[2], на территории области за данный период произошло 19645 пожаров, наибольшее количество (2224) в 2006 году, а наименьшее (1355)в 2016 году(рис.1).

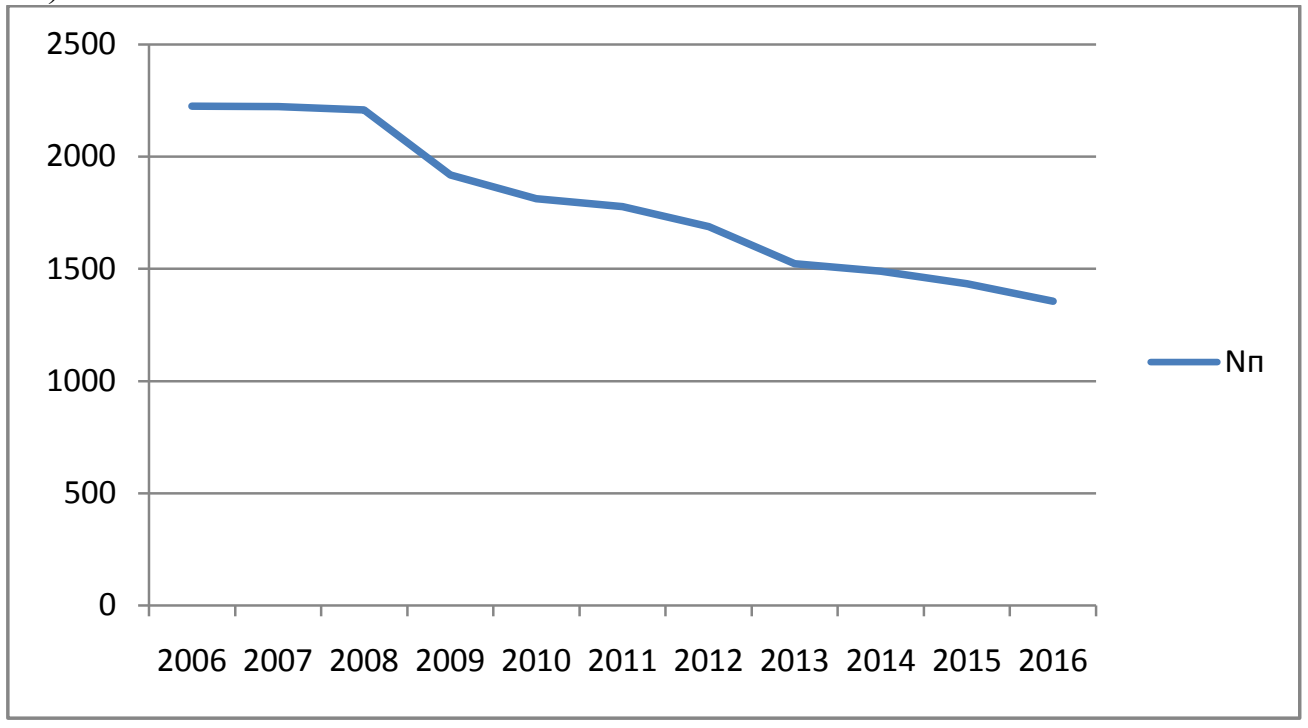

Временная диаграмма количества пожаров в Амурской области (2006-2016 г2.)

Преобладающее количество пожаров происходит в городах и поселках городского типа, в общей сложности пожары в таких населенных пунктах занимают 65\% от общего количества пожаров, остальная часть приходится на сельские населенные пункты. Динамика изменения количества пожаров в городах и селах, представлена на рисунке 2.По кривой отображающей пожары в городах видна положительная динамика, количество пожаров в городах и пгт за расчетный период снизилось на 45,3\%, в сельских населенных пунктах так же просматривается снижение количества возгораний, но в отличие от городов, снижение произошло всего на 25,7 \%.

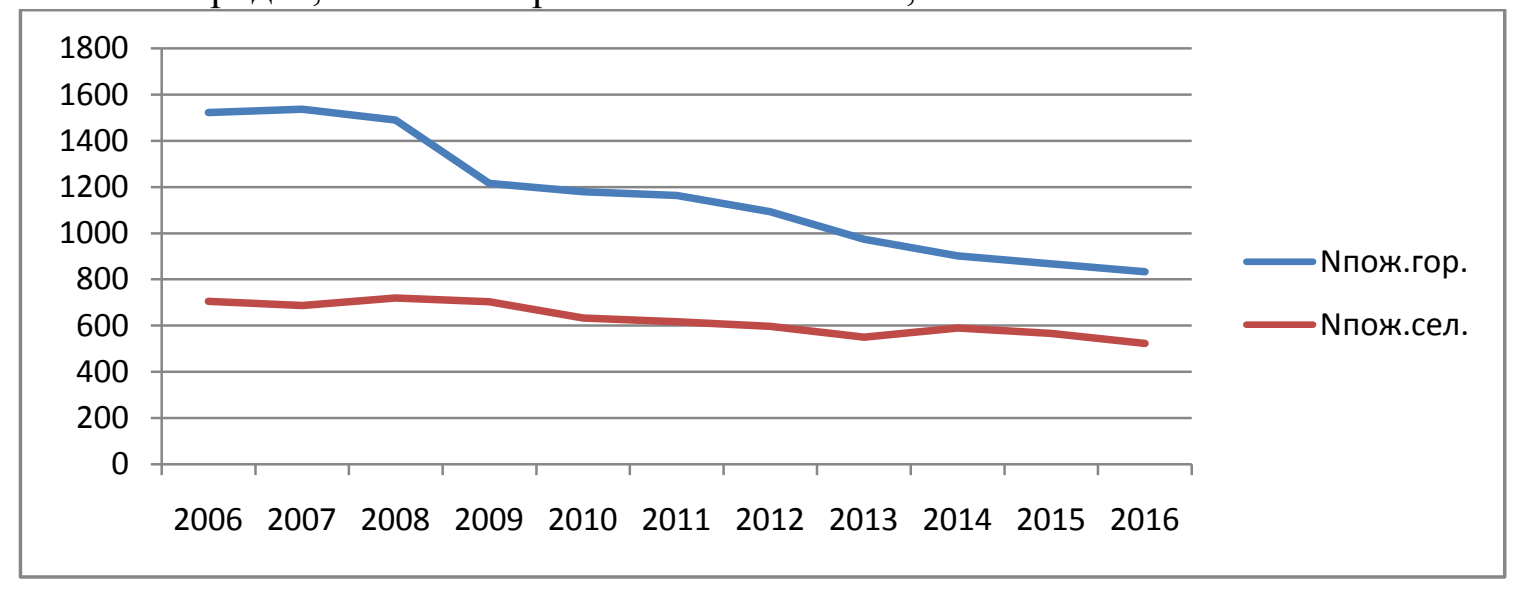

Временная диаграмма динамики изменения количества пожаров в городах и селах Амурской области(20062016 22.)

Одной из основных причин пожаров(23\% от всего количества пожаров) является нарушение правил устройства и эксплуатации электрооборудования(НПУиЭ электрооборудования). В данную группу входит очень широкий перечень причин, в том числе и пожары вызванные коротким замыканием. Короткое замыкание может происходить по причине чрезмерного нагрева нулевого проводника, вызванного асимметрией фазных токов в трехфазной сети. Во время протекания по нулевому проводнику тока большего чем номинальный, происходит его чрезмерный нагрев, 
который в свою очередь вызывает большие электрические потери и ускоренное старение изоляции, ее разрушение в последствии.

Всего за расчетный период произошло 4664 пожара по причинеНПУиЭ электрооборудования. Наибольшее количество пожаров по вышеуказанной причине зафиксировано в 2010 году и составило 463, наименьшее количество (365) произошло в 2015г(рис.3).Процент пожаров от общего их количества, по причине нарушения ПУиЭ электрооборудования,остается стабильно высоким на протяжении всего исследуемого периодаи составляет: 2006г. - 19,6\% ; 2007г. - 19,0\% ; 2008г. - 19,5\% ; 2009г. - 22,8\% ; 2010 г. $-25,6 \% ; 2011$ г. $-25,1 \%$; 2012г. $-25,9 \%$; 2013г. $-28,5 \% ; 2014$ г. $-28,1 \% ; 2015$ г. $25,5 \% ; 2016$ г. $-27,6 \%$.

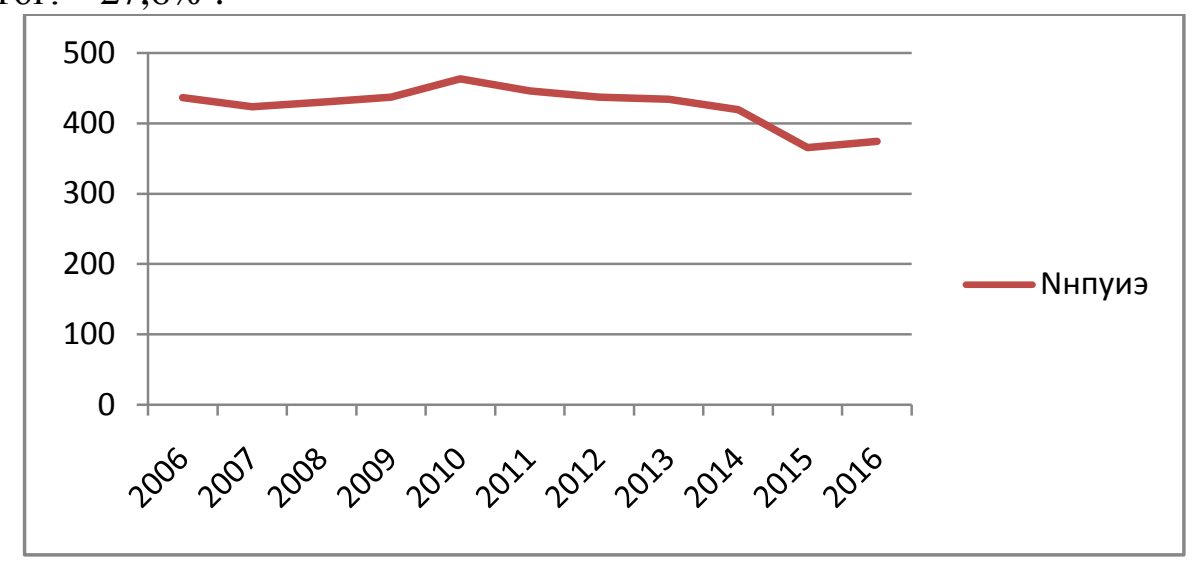

Временная диаграмма количества пожаров в Амурской области по причине нарушения правил устройства и эксплуатации электрооборудования (2006-2016 г2.)

Одной из причин связанной с высоким процентом таких пожаровявляется ежегодное увеличение количества электрооборудования у населения. На рисунке 4 отчетливо видно что стабильно в течении выбранного периода подавляющее большинство пожаров имеет место на объектах жилого фонда. Преимущественно коммунально-бытовой характер такой нагрузки, еe непрогнозируемый характер появления, влечет за собой возникновение кроме неслучайной несимметрии токов, несимметрии статической(случайной) или вероятностной, которая достигает значительных величин. [3]

Любой пожар несет в себе большой материальный ущерб, так минимальный материальный ущерб зафиксирован в 2015 году и составил 16,14 млн. руб., а максимальный в 2012г. - 152,2 млн. руб. Динамика изменения причиненного материального ущерба отражена на рисунке 5.

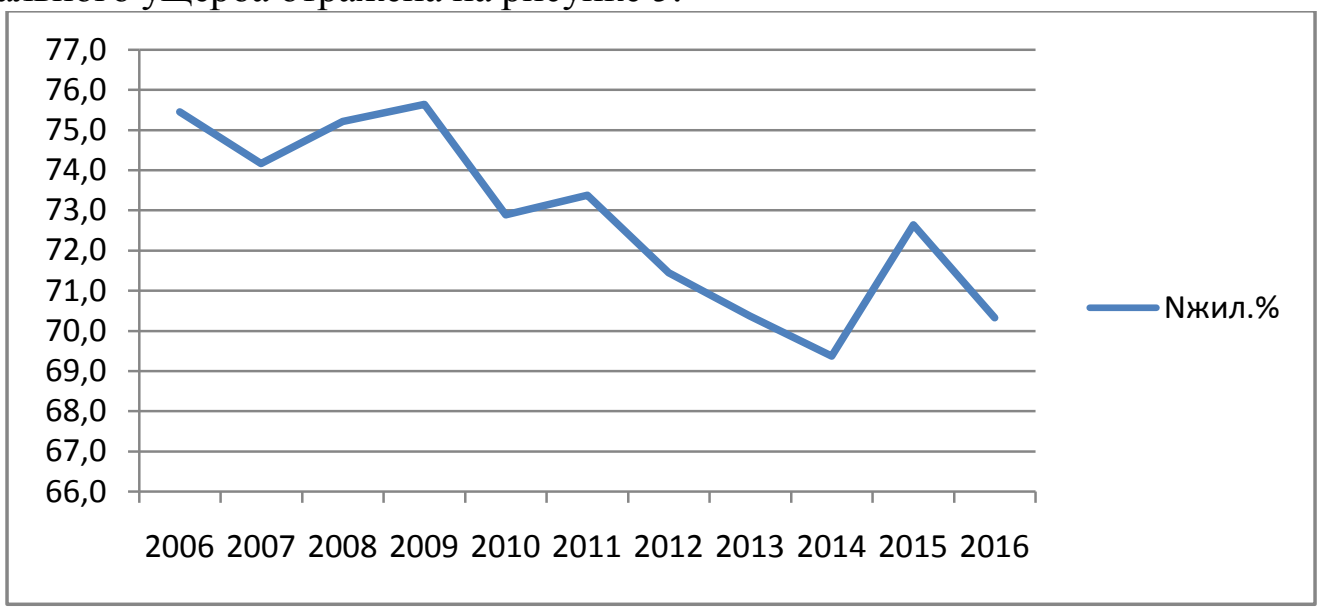

Временная диаграмма изменения процентного соотношения пожаров в жилом секторе от общего количества пожаров (2006-2016 г2.) 


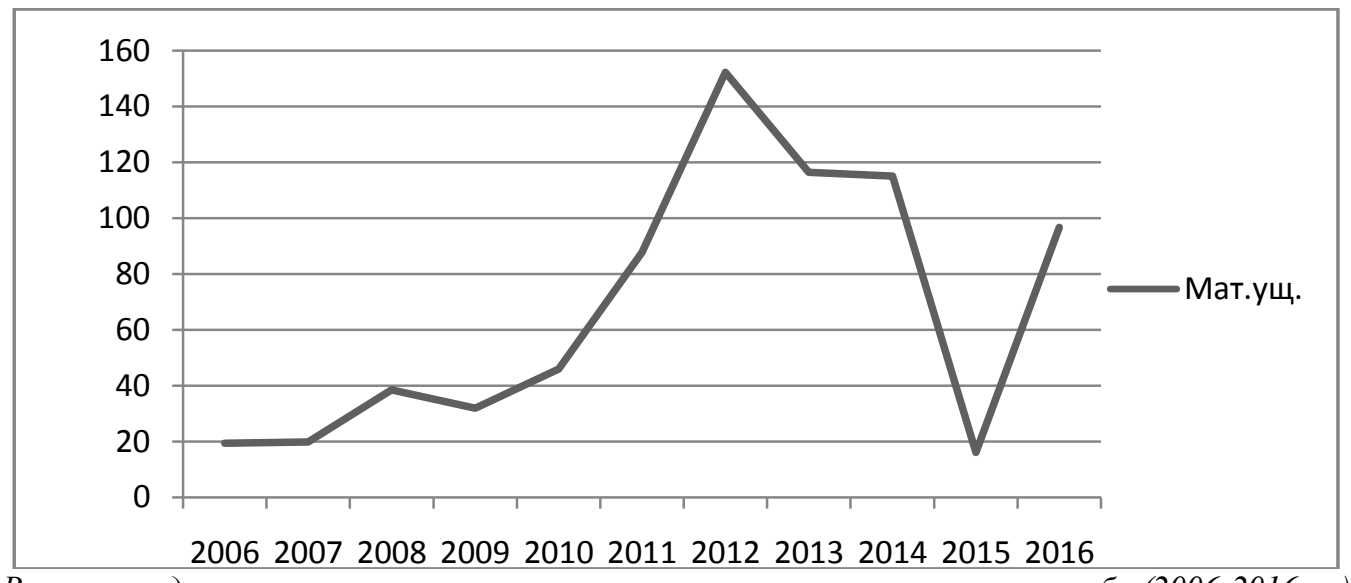

Временная диаграмма изменения количества причиненного пожарами ущерба (2006-2016 г2.)

Неправильная эксплуатация электрооборудования и нарушение правил его устройства, а вследствие этого и возгорание несет в себе, помимо материальных убытков, человеческие жертвы. За исследуемый период(2006-2016гг.) в огне погибли 1447 человек, из них 76 детей, травмировано 1184 человека, из них детей 144 человека. Исходя из полученных данных, выявляется положительная тенденция, с каждым годом происходит постепенное уменьшение количества погибших и пострадавших в пожарах, наглядное представление этого отображено на рисунке 6.

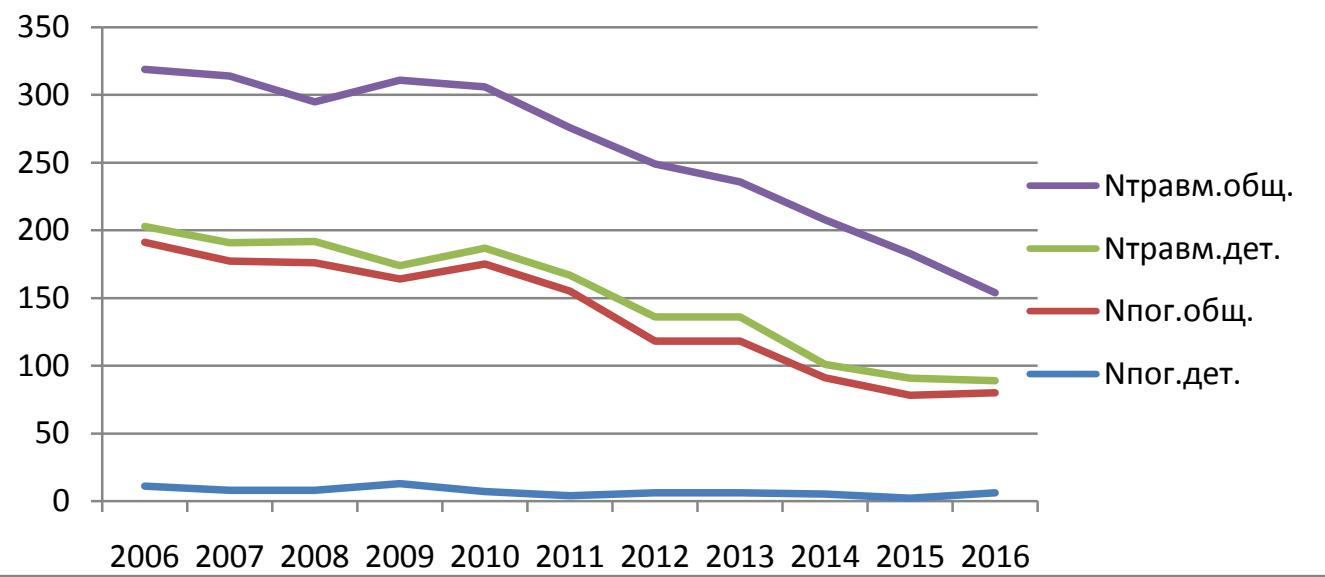

Временная диаграмма изменения количества погибших и пострадавших при пожарах в Амурской области (2006-2016 г2.)

Для уменьшения количества пожаров в жилых и производственных помещениях необходимо исключить одну из возможных причин возникновения пожаров асимметрию токов и напряжений. Применение средств симметрирования напряжений и других мероприятий, направленных на снижение потерь и повышение качества электрической энергии позволит снизить количество пожаров и ущерб от них, за счет уменьшения токов нулевой последовательности, что приведет к снижению температуры нулевого проводника и увеличению срока службы проводникового материала.

$$
* * *
$$

1. Подъячих Сергей Валерьевич. Нормализация качества электрической энергии в сельских сетях 0,38 КВ при несимметричной нагрузке для снижения энергетических потерь :Дис. ... канд. техн. наук : 05.20.02 : Иркутск, 2003244 с. РГБ ОД, 61:04-5/1052.

2. Главное управление МЧС России по Амурской области: Адрес: 675000, г. Благовещенск, ул. Пионерская, д. 47.

3. Иванов Д.А. Симметрирующее устройство для трехфазной четырехпроводной сети с регулируемыми параметрами [Текст] /И.В. Наумов, Д.А. Иванов//ВестникКрасГАУ -2007 - №4 - С 191-194. 